\title{
Inter-Organisational Knowledge Transfer Process Model
}

\author{
Shizhong Chen \\ University of Luton, UK \\ Yanqing Duan \\ University of Luton, $U K$ \\ John S. Edwards \\ Aston Business School, UK
}

\section{INTRODUCTION}

Knowledge management (KM) is an emerging discipline (Ives, Torrey \& Gordon, 1997) and characterised by four processes: generation, codification, transfer, and application (Alavi \& Leidner, 2001). Completing the loop, knowledge transfer is regarded as a precursor to knowledge creation (Nonaka \& Takeuchi, 1995) and thus forms an essential part of the knowledge management process. The understanding of how knowledge is transferred is very important for explaining the evolution and change in institutions, organisations, technology, and economy. However, knowledge transfer is often found to be laborious, time consuming, complicated, and difficult to understand (Huber, 2001; Szulanski, 2000). It has received negligible systematic attention (Huber, 2001; Szulanski, 2000), thus we know little about it (Huber, 2001). However, some literature, such as Davenport and Prusak (1998) and Shariq (1999), has attempted to address knowledge transfer within an organisation, but studies on inter-organisational knowledge transfer are still much neglected.

An emergent view is that it may be beneficial for organisations if more research can be done to help them understand and, thus, to improve their interorganisational knowledge transfer process. Therefore, this article aims to provide an overview of the inter-organisational knowledge transfer and its related literature and present a proposed inter-organisational knowledge transfer process model based on theoretical and empirical studies.

\section{BACKGROUND: AN OVERVIEW OF KNOWLEDGE TRANSFER AND RELATED LITERATURE}

\section{Knowledge Transfer within an Organisation}

Knowledge transfer implies that knowledge is transferred from the sender(s) (person, group, team, or organisation) to the recipient(s) (person, group, team, or organisation) (Albino, Garavelli \& Schiuma, 1999; Lind \& Persborn, 2000). It may happen within an organisation or between organisations. Szulanski (2000) argues that knowledge transfer is a process in which difficulty should be seen as its characteristic feature. This process view may help organisations identify difficulties in the knowledge transfer. $\mathrm{He}$ further proposes a process model for intraorganisational knowledge transfer as shown in Figure 1, which contains four stages: initiation, implementation, ramp-up, and integration.

In the initiation stage, the effort aims to find an opportunity to transfer and to decide whether to pursue it. An opportunity to transfer exists as soon as the seed for that transfer is formed, that is, as soon as a gap is found within the organisation, and the knowledge to address the gap is thought to be available. In the implementation stage, following the decision to transfer knowledge, attention shifts to the exchange of information and resources between the source and the recipient, that is, "learning before doing" for the recipient. In the ramp-up 
Figure 1. The process for knowledge transfer within an organisation (Szulanski, 2000)

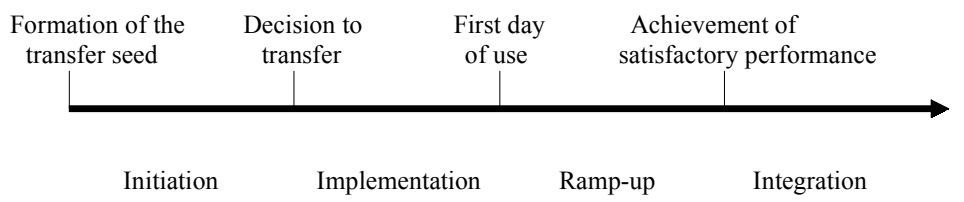

stage, the recipient begins using acquired knowledge, and tries to ramp-up to satisfactory performance, that is, "learning by doing" for the recipient. In the integration stage, the recipient takes subsequent follow-through and evaluation efforts to integrate the practice with its other practices (Szulanski, 2000).

The process model demonstrates that knowledge transfer within an organisation is complex and difficult. However, knowledge transfer between organisations is even harder and more complicated. When knowledge is transferred within an organisation, the organisation should try to expand the amount of shared knowledge among its employees to an appropriate level (or to the highest level possible) (Lind \& Seigerroth, 2000) so as to develop (or preserve) its competitive advantage. When transferring knowledge between organisations, the organisations have to face "the boundary paradox" (Quintas, Lefrere \& Jones, 1997), which involves more complicated factors impinging on the transaction. It also requires the negotiation between participating parties, strict governance mechanisms to regulate the transfer content, and higher loyalty by relevant employees.

\section{Inter-Organisational Knowledge Transfer}

Inter-organisational knowledge transfer may have different types. For instance, von Hippel (1987) classifies know-how trading between firms into two types: informal and formal. He defines informal know-how trading as the extensive exchange of proprietary know-how by informal networks in rival (and nonrival) firms. Here is an example, when a firm's engineer who is responsible for obtaining or developing the know-how his/her firm needs finds that the required know-how is not available in-house or in public sources; the engineer may, through his/ her private relationships, seek the needed information from professional counterparts in rival (and nonrival) firms. Formal know-how trading is referred to as official knowledge exchange agreements between firms such as agreements to perform $R \& D$ cooperatively or agreements to license or sell proprietary technical knowledge (von Hippel, 1987). von Hippel further argues that the main differences between the informal and formal trading are (1) the decisions to trade or not trade proprietary know-how in the former are made by individual, knowledgeable engineers; no elaborate evaluations of relative rents or seeking of approvals from firm bureaucracies are involved; however, the decisions for the latter are made by firm bureaucracies; (2) the value of a particular traded module in the former is too small to justify an explicit negotiated agreement to sell, license, or exchange, but the traded module in the latter is of considerable value. In fact, the fundamental difference between the so-called informal and formal inter-organisational knowledge transfer is that the former is carried out through employees' private relationships without the direct involvement of their corporate management, but the latter has direct involvement of their corporate management.

This article is mainly concerned with the formal knowledge transfer process between organisations.

\section{Inter-Organisational Learning}

From an organisational learning perspective, interorganisational knowledge transfer is actually the process of organisations learning from each other, that is, inter-organisational learning.

Organisational learning may occur when the organisation acquires information (knowledge, understanding, know-how, techniques, or practices) of any kind and by whatever means (Argyris \& Schon, 1996). It is individuals that make up an organisation; thus each organisational learning activity actually begins from individual learning. Individual learning is a necessary condition for organisational learning which is institutionally embedded (Beeby \& Booth, 
2000). However, individual learning is not sufficient. It is generally accepted that the acquisition of knowledge by individuals does not represent organisational learning (Beeby \& Booth, 2000; Nonaka \& Takeuchi, 1995). To achieve the necessary cross-level effects, that is, successful organisational learning, individual learning should be on the organisation's behalf (Argyris \& Schon, 1996) and must be shared through communication which is supported by institutional processes for transferring what is learned by individuals to the organisation as well as for storing and accessing that which is learned (Beeby \& Booth, 2000).

Literature review shows that study on organisational learning mainly focuses on learning within an organisation, that is, on how to convert individual learning into organisational learning once the individuals have acquired the needed knowledge. Issues related to how and from where the individuals acquire the needed knowledge are more or less ignored. When organisations learn from each other, it is normally some individuals who learn on their organisation's behalf from other individuals on another organisation's behalf. Then the learner's individual learning will be further converted into organisational learning. Therefore, inter-organisational knowledge transfer process, as a kind of inter-organisational learning, can be divided into two subprocesses: (1) inter-employee learning between employees from different organisations and (2) organisational learning within the receiving organisation by converting individual learning to organisational learning through the organisation's internal mechanisms (Chen, Duan \& Edwards, 2002).

\section{Social Networks}

Social relationships play an important role in social networks. Granovetter (1985) points out that all activities are embedded in complex networks of social relations which include family, state, educational and professional background, religion, gender, and ethnicity.

From the social network perspective, inter-organisational knowledge transfer activities can be regarded as activities within social networks. Assuming the influence from a third party is ignored, the network may have four actors: receiving organisation and receiving employee, giving organisation and
Figure 2. The relationship mechanism for interorganisational knowledge transfer

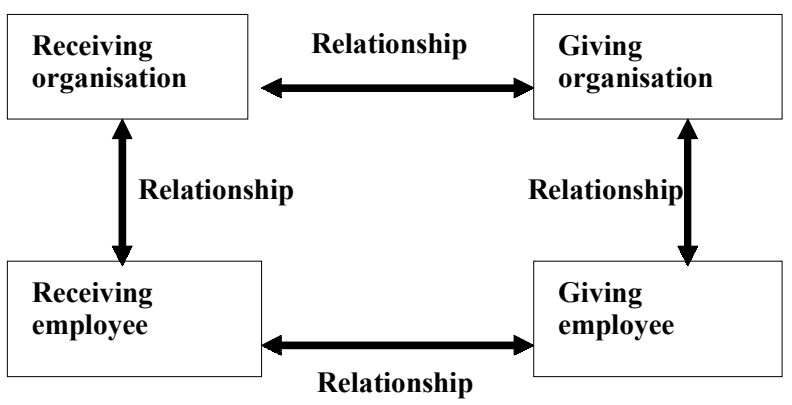

giving employee. The actors' behaviours will be influenced by their relationships. In the first subprocess (i.e., inter-employee learning between employees from different organisations), when the receiving organisation requests knowledge from the giving organisation, they will establish their own knowledge transfer strategies based on the relationship between two organisations. Then the organisations may use their relationships with their own employees to influence and guide the employees' learning behaviours to conform to their knowledge transfer strategies. The personal relationship between the receiving and giving employees will also influence their individual learning effectiveness. In the second subprocess, the relevant actors will be the receiving organisation and receiving employee. The key point for the receiving organisation is to establish its internal mechanisms to promote the conversion from the receiving employee's individual learning into organisational learning. The internal mechanisms may be considered as being embedded in the relationship between the receiving organisation and receiving employee. Therefore, there is a relationship mechanism, as depicted in Figure 2. This mechanism coordinates and influences the relevant actors' behaviours for interorganisational knowledge transfer.

\section{AN INTER-ORGANISATIONAL KNOWLEDGE TRANSFER PROCESS MODEL}

Through the above review, it is known that interorganisational knowledge transfer process can be divided into two subprocesses. Drawing on 
Szulanski's (2000) process model in Figure 1, the first subprocess can be further divided into three stages: initiation, selection, and interaction; the second subprocess may be called conversion. So, a similar four-stage model for inter-organisational knowledge transfer is offered in Figure 3.

In the initiation stage, two organisations try to find an opportunity to transfer and to decide whether to pursue it through negotiation. In the selection stage, the receiving and giving organisations select an employee as a receiving and giving employee respectively (more than one employee may be involved, of course, in either organisation). In the interaction stage, the giving employee transfers his/ her knowledge to the receiving employee. In the conversion stage, the receiving employee transfers his/her acquired knowledge to his/her employerthe receiving organisation. The conversion stage is only related to the receiving organisation and receiving employee.

The relationship between the process model in Figure 3 and Szulanski's (2000) process model may be seen as follows: (1) The initiation and interaction stages of the former are similar to the initiation and implementation stages of the latter. (2) In the conversion stage of the former, the receiving employee plays two roles: first, he/she, as a recipient, will apply his/her acquired knowledge to his/her work and have to experience the ramp-up and integration stages; second, he/she is also a source for his organisation as his/her colleagues may learn from him/her. So, the conversion stage contains the ramp-up and integration stages, as well as the whole transfer process within an organisation.

Based on Figures 2 and 3, annd in addition to suggestions from some empirical evaluation with company managers (e.g., the initiation stage should be further divided into two stages: identification and negotiation to highlight their importance), a process model can be proposed for the inter-organisational knowledge transfer and is illustrated in Figure 4. The following explanation is provided for the five stages, although there may be no clear-cut division between them.

1. Identification: In this stage, the receiving company internally finds its knowledge gap, identifies its needs for acquiring external knowledge and the external knowledge source.

2. Negotiation: In this stage, the receiving company negotiates (or discusses) with the giving company on the knowledge transaction, or any problems happening in the transfer process, to reach an agreement or oral commitment.

3. Selection: It is a stage in which a giving (or receiving) employee is selected by the giving (or receiving) organisation to specifically carry out the agreed transfer task.

4. Interaction: It is a stage in which both the giving and receiving employees iteratively contact each other to transfer the agreed knowledge.

5. Conversion: It occurs when the receiving employee contributes his/her acquired knowledge to the employer (i.e., the receiving organisation), the individual learning will be converted into organisational learning to successfully improve the receiving organisation's business.

The proposed process model not only identifies the important stages in the inter-organisational knowledge transfer process, but also shows the dynamic interactions between the organisations involved. More importantly, the model emphasises the repetitive nature of the process among stages and demonstrates the necessity of iterative loops between some stages. The transfer process may, sometimes not simply progress in the stage sequence but in iterative loops, as it may be necessary to go back to the previous stage. For example, once the receiving organisation initially identifies its needs for acquiring

Figure 3. The inter-organisational knowledge transfer process

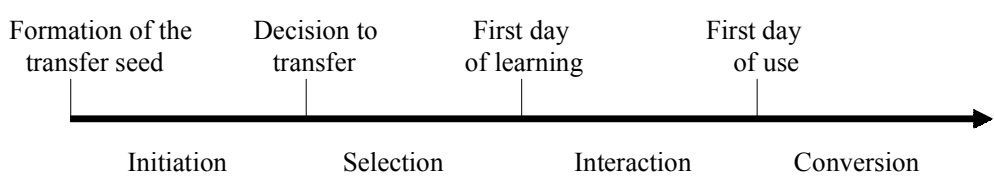


Figure 4. The inter-organisational knowledge transfer process model

Receiving Organisation Giving Organisation
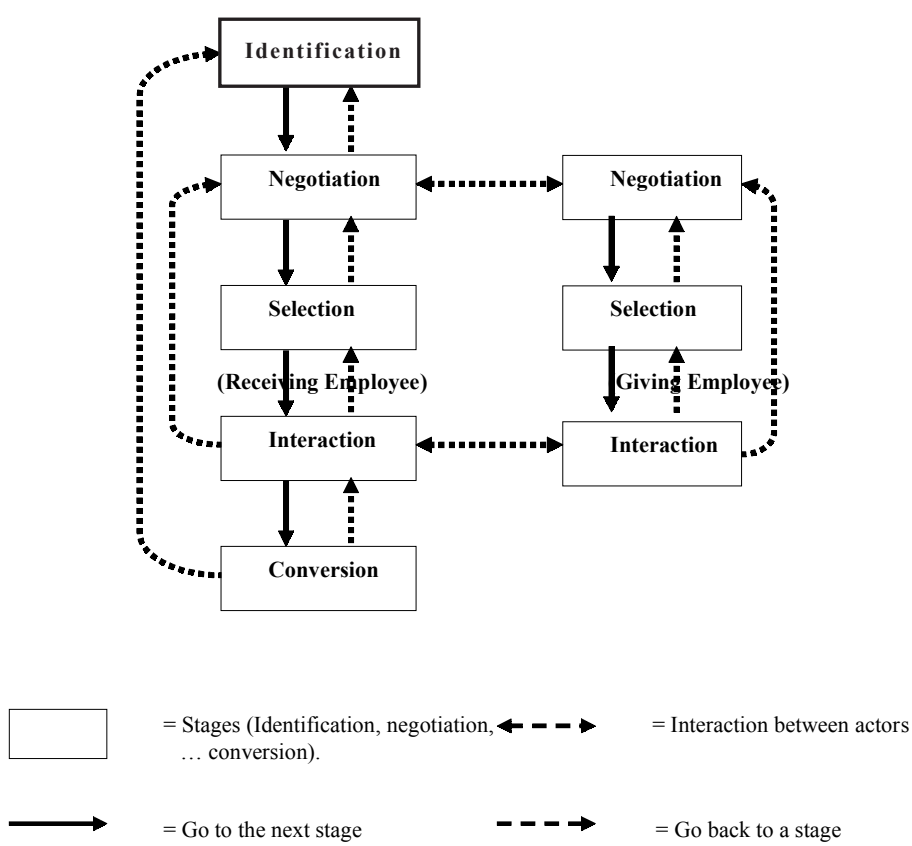

external knowledge and the external knowledge source (i.e., the giving organisation), the former will negotiate or discuss with the latter to further clarify what the former exactly wants. Sometimes, the needs initially identified by the receiving organisation may be found to be inaccurate; thus it is necessary for the receiving company to go back to the identification stage to further clarify its needs. Then it will negotiate or discuss with the giving organisation again. This process may carry on until the true needs for the receiving organisation are correctly identified. Although the selection of a receiving employee is the receiving organisation's internal affair, sometimes the receiving organisation may inform or consult the giving organisation about its arrangements for the receiving employee. So, there is a feedback loop that goes from the selection stage to the negotiation stage until the receiving employee is finally selected. Further, the transfer process in the receiving organisation may also have iterative loops during its interaction with the giving organisation. Similar things may happen in the giving organisation as well.

In the conversion stage, the receiving employee will apply the acquired knowledge into the receiving organisation's business. The receiving employee may still need the giving employee's help because he/she may not fully understand the acquired knowledge or not fully absorb the knowledge needed for the application. This will initiate a feedback loop from the conversion stage to the interaction stage, then back to the conversion stage again. Furthermore, different organisations have different environments. The application of the knowledge in the new environment may trigger some new problems, which may cause the receiving organisation to identify its new needs for knowledge acquisition. Some of them may be internally met in the conversion stage. Some of them may cause the receiving organisation to seek a new external knowledge source and begin a new round of inter-organisational knowledge transfer. So, there is a backward loop from the conversion stage to the identification stage.

\section{CONCLUSION}

Through a review of the relevant literature on knowledge transfer, organisational learning and social networks, an inter-organisational knowledge trans- 
fer process model is developed. As shown in the model, inter-organisational knowledge transfer is a complex process and difficult to understand. As a result, the success of the transfer can be affected by many factors and pose serious challenges to organisations. Some empirical research has been carried out to test the model, and the preliminary findings suggest that managers feel that the process model is a sound attempt to reflect companies' knowledge transfer practices and can help the companies to better understand the nature, the mechanism, and the process of the knowledge transfer.

\section{FUTURE TRENDS}

Future research needs to be undertaken to identify the important factors in each stage. For instance, in the interaction stage, the receiving employee will learn from the giving employee, the former's absorptive capacity and prior experience, the latter's openness, prior experience and expressiveness, as well as the trust between both of them (Cohen \& Levinthal, 1990; Wathne, Roos \& von Krogh, 1996; Chen, Duan, \& Edwards, 2002) could be identified as the important factors for the stage. Furthermore, inter-organisational knowledge transfer strategies for both receiving and giving organisations can be developed to help them to address the "boundary paradox" (Quintas, Lefrere, \& Jones, 1997) more effectively and maximise the potential benefits of knowledge sharing for both organisations involved.

\section{REFERENCES}

Alavi, M., \& Leidner, D. (2001). Knowledge management and knowledge management systems: Conceptual foundations and research issues. MISQ Quarterly, 25(1), 107-136.

Albino, V., Garavelli, A. C., \& Schiuma, G. (1999). Knowledge transfer and inter-firm relationships in industrial districts: The role of the leader firm. Technovation, 19, 53-63.

Argyris, C., \& Schon, D. A. (1996). Organisational learning II: Theory, method, and practice. London: Addison-Wesley.
Beeby, M., \& Booth, C. (2000). Networks and interorganisational learning: A critical review. The Learning Organisation, 7(2), 75-88.

Chen, S., Duan, Y., \& Edwards, J. S. (2002, September 24-25). Towards an inter-organisational knowledge transfer framework for SMEs. Proceedings of the $3^{\text {rd }}$ European Conference on Knowledge Management, Dublin, Ireland.

Cohen, W. M., \& Levinthal, D. A. (1990). Absorptive capacity: A new perspective on learning and innovation. Administrative Science Quarterly, 35, 128-152.

Davenport, T. H., \& Prusak, L. (1998). Working knowledge: How organisations manage what they know. Boston: Harvard Business School Press.

Granovetter, M. (1985). Economic action and social structure: The problem of embeddedness. American Journal of Sociology, 91(3), 481-510.

Huber, G. (2001). Transfer of knowledge in knowledge management systems: Unexplored issues and suggested studies. European Journal of Information Systems, 10, 72-79.

Ives, W., Torrey, B., \& Gordon, C. (1997). Knowledge management: An emerging discipline with a long history. Journal of Knowledge Management, 1(4), 269-274.

Lind, M., \& Persborn, M. (2000, September 12-14). Possibilities and risks with a knowledge broker in the knowledge transfer process. Proceedings of the $42^{\text {nd }}$ Annual Conference of the Operational Research Society, University of Wales, Swansea.

Lind, M., \& Seigerroth, U. (2000, September 12-14). Development of organisational ability through teambased reconstruction: Going from personal to shared contextual knowledge. Proceedings of the $42^{\text {nd }}$ Annual Conference of the Operational Research Society, University of Wales, Swansea.

Nonaka, I., \& Takeuchi, H. (1995). The knowledge-creating company. Oxford: Oxford University Press.

Quintas, P., Lefrere, P., \& Jones, G. (1997). Knowledge management: A strategic agenda. Long Range Planning, 30(3), 385-391. 
Shariq, S. Z. (1999). How does knowledge transform as it is transferred? Speculations on the possibility of a cognitive theory of knowledgescapes. Journal of Knowledge Management, 3(4), 243251.

Szulanski, G. (2000, May). The process of knowledge transfer: A diachronic analysis of stickiness. Organisational Behaviour and Human Decision Process, 82(1), 9-27.

von Hippel, E. (1987). Cooperation between rivals: Informal know-how trading. Research Policy, 16, 291-302.

Wathne, K., Roos, J., \& von Krogh, G. (1996). Towards a theory of knowledge transfer in a cooperative context. In G. von Krogh \& J. Roos (Eds.), Managing knowledge: Perspectives on co-operation and competition. London: Sage.

\section{KEY TERMS}

Absorptive Capacity: Reflects the receiving employee's ability to absorb the knowledge sent by the giving employee.
Boundary Paradox: In the knowledge transfer process, the giving and receiving organisations' borders must be open to flows of information and knowledge from the networks and markets in which they operate, but, at the same time, the organisation must protect and nurture its own knowledge base and intellectual capital.

Expressiveness: The ability of giving employees to use oral or facial expression and body language to clearly express what they know.

Knowledge Transfer: Knowledge is transferred from the sender(s) (person, group, team, or organisation) to the recipient(s) (person, group, team, or organisation).

Openness: The giving employees' willingness to transfer their knowledge in a collaborative interaction. This stresses the attitude of giving employees involved in the knowledge transfer of not hiding their knowledge so that potential learning is facilitated.

Social Network: Refers to a set of social entities (or persons) and social relationships which connect them.

Trust: A social actor extrapolates that another actor will behave as expected. Trust is a risky engagement. 